\title{
TRANSCRIPTION EXPRESSION OF GENE ENCODING CATHELICIDIN CATHL4 IN VIETNAM INDIGENOUS YELLOW CATTLE
}

\author{
Do Thi Tuoi ${ }^{1}$, Tran Thi Thuy Anh', Pham Doan Lan², Nguyen Thi Hong Van ${ }^{1, *}$ \\ ${ }^{1}$ VNU University of Science, Vietnam National University, Hanoi \\ ${ }^{2}$ Key Laboratory of Animal Cell Technology, National Institute of Animal Sciences
}

Received 3 September 2020, accepted 18 February 2021

\begin{abstract}
Cathelicidins, a family of host-defence peptides, are present in a diverse range of species, including fish, amphibians, birds, reptiles, and mammals. The evidence for the role of these cationic antimicrobial peptides in innate host defenses is convincing from the data of animal model and transgenic animal experiments as well as wildlife or domestic animals, indicating that the peptides protect against inflammatory and immune system after induction by bacterial infection. In this study, we present the assessment of transcription expression of CATHL4 gene which encodes indolicidin, a cathelicidin from indigenous yellow cattle of Vietnam. The research focused on RNA samples extracted from lung tissues and lymph node collected from diseased cattle which died of infectious respiratory symptoms and the healthy cattle which were slaughtered for food purposes. By quantitative real-time PCR, the relative expression of transcripts was determined and analyzed using the expression of $Y W H A Z$ gene as reference. The results showed that this gene was abundantly expressed at a higher level in tissues of the diseased cattle than in those of the healthy ones. In both infection and healthy states, the expression of CATHL4 in lymph nodes were higher than in lung tissues. This indicated that CATHL4 (indolicidin) may participate in functions against infectious pathogens.
\end{abstract}

Keywords: Vietnamese Yellow cattle, cathelicidins, CATHLA gene, transcription level, qRT-PCR.

Citation: Do Thi Tuoi, Tran Thi Thuy Anh, Pham Doan Lan, Nguyen Thi Hong Van, 2021. Transcription expression of gene encoding cathelicidin CATHLA in Vietnam indigenous yellow cattle. Academia Journal of Biology, 43(1): 77-84. https://doi.org/10.15625/15457

*Corresponding author email: nguyenthihongvan@ hus.edu.vn

(O2021 Vietnam Academy of Science and Technology (VAST) 


\section{INTRODUCTION}

Cathelicidins are a group of host defense peptides (HDPs) which include a diverse family of endogenous cationic antibiotic peptides present in all mammalian species. These HDPs are diverse cationic amphipathic short peptides which have both antimicrobial and immunomodulatory activities and play an important role in both innate and adaptive immunity by neutralizing invading pathogens. The family of these HDPs was named due to their conserved $\mathrm{N}$-terminal domain that shares high homology with cathelin, an inhibitor of the cysteine proteinase cathepsin L (Shinnar, 2003; Wuerth, 2011). These HDPs are conservative, which contain a signal peptide with a highly conserved cathelin-like domain and a mature peptide consisting of about 40 amino acids (Zhang, 2019). In the cathelicidin structure, the C-terminal antimicrobial domain (AMD) is highly variable. This property satisfies the functional diversity of this antimicrobial peptide (AMP) family. After translation, cathelicidins are precursor pre-pro-peptides and only act as AMPs after proteolytic cleavage. In the mature peptide structure, these HDPs are unusually rich in amino acids such as proline, arginine, and tryptophan and form the secondary structures such as $\alpha$ helix, $\beta$-hairpin, and random coils (Tomasinsig, 2005). Precursor CATHLs may be found in myeloid cells, epithelial cells of the skin, oral mucosa, and the gastrointestinal tract. However, the mature forms of these HDPs are found at mucosal surfaces and within bodily secretions such as sweat, breast milk, and saliva (Mookherjee, 2006). Cathelicidin gene-cluster in the bovine and buffalo genome was characterized and sites of expression in the bovine mammary gland were identified (Gillenwaters et al., 2009, Whelehan et al., 2014, Brahma, 2015). Bioinformatic analysis showed that there were seven protein-coding cathelicidin genes (CATHL1-7) clustered on the long arm of chromosome 22 of bovine including CATHL1 (Bac1), CATHL2 (Bac5), CATHL3 (Bac7), CATHL4 (indolicidin), CATHL5 (BMAP-28), CATHL6 (BMAP-27), and $C A T H L 7$ (BMAP-34), in which there are two identical copies of CATHL4, and three additional putative cathelicidin genes. That study also found the constitutive expression of six cathelicidin genes in the mammary gland and the expression did not increase during infection caused by Staphylococcus aureus.

To understand the role of these cathelicidins in the host protection, many studies have been conducted to determine the expression of cathelicidin genes in vivo. Broekman et al. isolated cathelicidin from Atlantic cod (Gadus morhua) to identify the structure and cleavage site of precursors, then examined the expression of these peptides in cod at 68 hours after hatching to confirm the activity of immune system in early development stage (Broekman, 2011). The expression of cathelicidins genes in forest musk deer (Moschus berezovskii) indicated that the six cathelicidin transcripts were abundant in the spleen and lung, and differently expressed in the musk deer which died of abscess disease. This result suggested that in forest musk deer, cathelicidins may be involved in infections (Zhang et al., 2019).

Vietnam indigenous cattle (Yellow cattle) are descendants of a crossbreed between Bos taurus and Bos indicus. They are called Yellow cattle for their yellow-lumped bull skin. In Vietnam and other South East Asian countries, the cattle play an important role in beef production and are often used for agriculture work and transportation Although the indigenous cattle breed is small stature, they can resist infectious disease and are highly adaptable to the monsoon-influenced tropical climate of Vietnam. Up to now, there has been no research on cathelicidin genes of indigenous cattle populations and the functional role of these genes in adaptation resistance to infectious diseases. The aims of this study were to identify the expression of 
the cathelicidin gene CATHLA at the transcription levels and to get a better understanding of the possible involvement of these peptides in the adaptive immune system by applying a quantitative real-time PCR approach. In our research, the mRNA abundance levels in the lung and lymph node tissues samples collected from both healthy and diseased individuals were examined and compared. This work may contribute to understanding the role of cathelicidins as host defense peptide in Vietnam indigenous cattle.

\section{MATERIALS AND METHODS}

\section{Collection of tissue samples}

Samples of lung tissue and lymph nodes were collected from two Yellow cattle immediately after death by respiratory disease and from two healthy Yellow cattle that had been slaughtered for food consumption. The diseased cattle had symptoms such as runny nose and mouth, fast and difficult breathing fast. Immediately after the animals died (the diseased ones) or were collected in slaughter (the healthy ones), tissue samples of lung and lymph node were cut into small pieces and kept in liquid nitrogen, and then stored at -80 ${ }^{\circ} \mathrm{C}$ until RNA extraction.

\section{RNA extraction and cDNA synthesis}

Frozen tissues were ground with a mortar in liquid nitrogen. Homogenization of ground tissue samples for RNA extraction was conducted with RNeasy Mini Kit (Qiagen) according to the manufacture's protocol and stored at $(-) 20{ }^{\circ} \mathrm{C}$. The RNA was then quantified, and its quality checked by gel electrophoresis on a $1 \%$ agarose gel. NanoDrop ${ }^{\mathrm{TM}} \quad 1000 \quad$ Spectrophotometer (Thermo Fisher Scientific) was used to check the quantity and quality of total RNA. RNA samples with absorbance ratios A260/280 and A260/230 of 2.0 with concentration of at least $50 \mathrm{ng} / \mu \mathrm{l}$ RNA were used for further analyses.

Synthesis of cDNA from total RNA by reverse transcription was conducted using the
RevertAid First Strand cDNA Synthesis Kit (Thermo Fisher Scientific). In the first step, 5 $\mu \mathrm{g}$ RNA was denatured at $65{ }^{\circ} \mathrm{C}$ for $5 \mathrm{~min}$ in the presence of $100 \mu \mathrm{M}$ oligo(dT). Next, reverse transcription was performed in a total volume of $20 \mu \mathrm{l}$ of mixture containing $5 \mu \mathrm{g}$ of RNA, $4 \mu \mathrm{l}$ of reverse transcriptase buffer, $2 \mu \mathrm{l}$ of $10 \mathrm{mM}$ deoxynucleotides, $1 \mu \mathrm{l}$ of protector RNase Inhibitor $(20 \mathrm{U} / \mu \mathrm{l})$, and $1 \mu \mathrm{l}$ of reverse transcriptase $(200 \mathrm{U} / \mu \mathrm{l})$. The mixture was incubated at $42{ }^{\circ} \mathrm{C}$ for $60 \mathrm{~min}$, then inactivated at $70{ }^{\circ} \mathrm{C}$ for $5 \mathrm{~min}$, and finally stored at (-) $20{ }^{\circ} \mathrm{C}$. The cDNA product was quantified using the NanoDrop ${ }^{\mathrm{TM}} 1000$ Spectrophotometer and then diluted to a $0.2 \mu \mathrm{g} / \mu \mathrm{l}$ working concentration.

\section{Examination of CATHL4 expression by quantitative Real-time PCR (qRT-PCR)}

The specific primers for the CATHLA gene and the reference gene YWHAZ (14-3-3 protein zeta/delta) (Goossens, 2005) in quantitative real-time PCR were designed by Primer 5.0 software according to the GenBank bovine sequences (Table 1) and synthesized by Intergrated DNA Technologies (IDT, USA) (Table 1). qRT-PCR was performed using the $\mathrm{SYBR}^{\circledR}$ Green-based fluorescent method and the real-time PCR 7500 system (Applied Biosystem) as follows: preincubation at $95^{\circ} \mathrm{C}$ for $2 \mathrm{~min}$, followed by 40 cycles of $95{ }^{\circ} \mathrm{C}$ for $15 \mathrm{sec}, 60{ }^{\circ} \mathrm{C}$ for $1 \mathrm{~min}$, and finally at $95^{\circ} \mathrm{C}$ for $1 \mathrm{~min}, 60^{\circ} \mathrm{C}$ for $1 \mathrm{~min}$ and $95^{\circ} \mathrm{C}$ for $30 \mathrm{sec}$. Total volume of reaction $10 \mu \mathrm{l}$ contains $5 \mu \mathrm{l}$ of GoTaq ${ }^{\circledR}$ qPCR Master Mix (Promega), $0.25 \mu 1$ of each primer with $10 \mathrm{pmol} / \mu \mathrm{l}$ concentration, $2 \mu \mathrm{l}$ of cDNA and Nuclease-Free $\mathrm{H}_{2} \mathrm{O}$. Dissociation curves were examined for the presence of one genespecific peak of single product. The qRT-PCR products were electrophorized on $2 \%$ agarose gels to confirm their predicted length. The products presented as a unique band of the expected size were used to analyze relative expression levels. A 5-fold dilution was established on the CATHL4 and YWHAZ genes in the qRT-PCR to determine reaction efficiency by constructing a relative quantification standard curve. 
Table 1. Gene specific primer sequences melting temperatures and amplicon lengths in qRT-PCR

\begin{tabular}{|c|c|c|c|c|c|c|}
\hline Gene & $\begin{array}{l}\text { Primer } \\
\text { name }\end{array}$ & $\begin{array}{c}\text { Nucleotide sequence } \\
\left(5^{\prime}-3^{\prime}\right)\end{array}$ & $\begin{array}{l}\text { Amplicon } \\
\text { length }\end{array}$ & $\begin{array}{l}\mathrm{Tm} \\
\left({ }^{\circ} \mathrm{C}\right) \\
\end{array}$ & $\begin{array}{l}\text { Spanning } \\
\text { exon }\end{array}$ & $\begin{array}{l}\text { Accession } \\
\text { number }\end{array}$ \\
\hline \multirow{2}{*}{ CATHLA } & qC4- F & $\begin{array}{l}\text { GACCTAAACTGTAAT } \\
\text { GAGCTCCAGAGT }\end{array}$ & \multirow{2}{*}{$99 b p$} & 56,6 & $\begin{array}{l}\text { Exon } 3 \text { to } \\
\text { Exon } 4\end{array}$ & \multirow{2}{*}{ NM_174827.2 } \\
\hline & qC4- R & $\begin{array}{c}\text { TCAGGATCTGACAG } \\
\text { CTCTTCTCCATCA }\end{array}$ & & 60.5 & Exon 4 & \\
\hline \multirow{2}{*}{$Y W H A Z$} & YWH-F & $\begin{array}{c}\text { AGACAGCATTTGAT } \\
\text { GAAGCCATTGCTG }\end{array}$ & \multirow{2}{*}{$121 \mathrm{bp}$} & 60 & $\begin{array}{l}\text { Exon } 4 \text { to } \\
\text { Exon } 5 \\
\end{array}$ & \multirow{2}{*}{ NM_174814.2 } \\
\hline & YWH-R & $\begin{array}{c}\text { TGGGTATCCGATGT } \\
\text { CCACAATGTCA }\end{array}$ & & 59.9 & $\begin{array}{l}\text { Exon } 5 \text { to } \\
\text { Exon } 6\end{array}$ & \\
\hline
\end{tabular}

\section{Analysis of qRT-PCR data}

The relative expression levels of CATHL4 gene in the tissues were analyzed using the 2 $\triangle \triangle C T$ method (Livak, 1997; Livak and Schmittgen, 2001) with YWHAZ as the reference gene. The Cq values of the CATHLA gene was normalized to that of the reference gene for both the healthy and diseased samples or for tissue comparison. Real-time PCR of each sample was repeated in triplicate and with a negative control (without cDNA). The expression levels of CATHLA gene were compared between the healthy and diseased cattle or between lung tissues and lympho node tissues in the same cattle. Data were analyzed by using the Student's t-test implemented in GraphPad Prism 5 (GraphPad Software, La Jolla, CA, USA) in which a P value of $\leq 0.05$ were considered significant.

\section{RESULTS}

\section{RNA extraction}

In this study, lymph node and lung tissue samples collected from two diseased and two healthy cattle were used for total RNA extraction and purification and the RNA products were checked by $1 \%$ agarose gel electrophoresis. The RNA samples were check by gel electrophoresis showed typical bands for total RNA. The quantity and quality of total RNA was estimated using NanoDrop ${ }^{\mathrm{TM}} 1000$ Spectrophotometer. The data confirmed that all of samples had absorbance ratios A260/280 and A260/230 of $\sim 2.0$ and concentration of the samples was at least $100 \mathrm{ng} / \mu \mathrm{l}$ RNA. These RNA samples were used for further analyses.

\section{qRT-PCR}

To examine the tissue expression pattern of CATHL4 in cattle lung and lymph node tissue, we used quantitative real-time PCR (qRT-PCR) to conduct the amplification of CATHL4 with specific primers from cDNA samples. The reaction products were checked by $2 \%$ agarose gel electrophoresis and result showed that amplicons were specific as expected. In Figure 1, one band for each reaction product appeared on gel at the lengths of $\sim 99 \mathrm{bp}$ and $120 \mathrm{bp}$ for CATHLA (Fig. 1A) and YWHAZ (Fig. 1B), respectively.

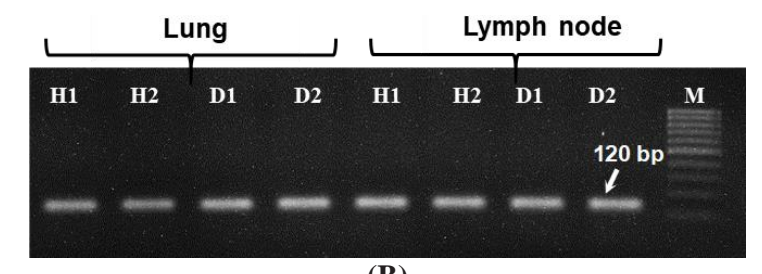

(B)

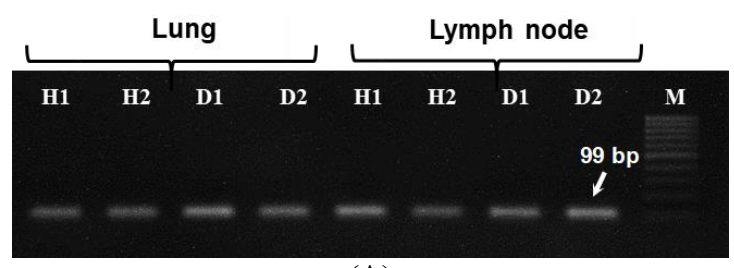

(A)
Figure 1. Gel electrophoresis of qRT-PCR products samples for amplification of CATHL4 (A) and $Y W H A Z$ (B) (loaded on $1 \%$ agarose gel stained with ethidium bromide). $\mathrm{H} 1, \mathrm{H} 2$ : the healthy cattle 1, 2; D1, D2: the diseased cattle 1, 2. Lane M: 100 bp DNA ladder (PhileKorea) 
To determine the amplification efficiencies of target and the reference genes, dissociation curves were established. The result indicated the presence of one gene-specific peak of single product and both the target and reference genes have similar amplification efficiencies. Melting curves of all products in amplification of CATHLA gene is presented in Fig. 2. Amplification curves for CATHLA (Fig. 2A) and YHAWZ (Fig. 2B) from eight cDNA

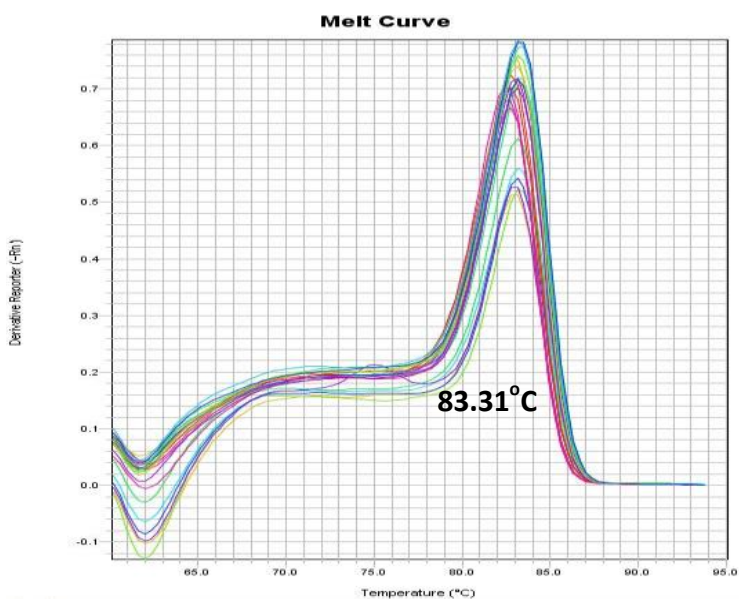

(A) samples and negative control without cDNA were shown. Eight amplicons for CATHLA had the same melting peaks at $83.31{ }^{\circ} \mathrm{C}$ and appeared as a single peak for each product of all samples. That was the same with $Y W H A Z$ with melting peaks at $79.61{ }^{\circ} \mathrm{C}$. The melting curve analysis indicated no signs of additional unspecific PCR products, i.e. the primer pairs were specific and the products lack contamination and primer-dimers.

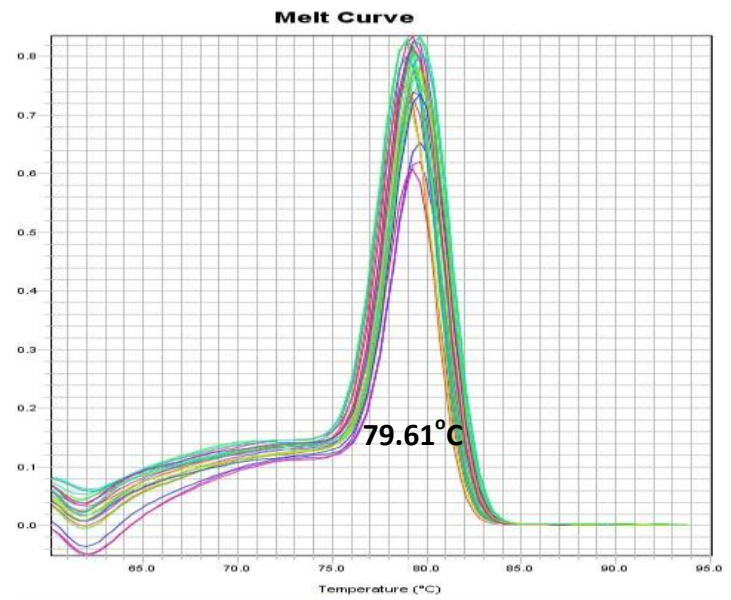

(B)

Figure 2. Melting curves for determination of specificity and efficiency of qRT-PCR amplification of CATHL4 (A) and YWHAZ (B) genes

The transcripts of CATHL4 gene were found in all investigated samples including the healthy and diseased cattle, as well as the lung and lymph node tissues, but at different levels. Data of transcription of interested gene in the samples showed the difference between tissues as well as between the healthy and infectious status. The relative expression levels of the cathelicidin gene CATHL4 in different samples were analyzed and YWHAZ expression was used as reference.

\section{qRT-PCR data analysis}

Comparison of CATHL4transcription level in tissues of the healthy cattle to that of the diseased cattle

To investigate whether the inflammatory and infectious status of cattle affect the expression of CATHL4 or not, CATHL4
mRNA expression in lymph node and lung tissues of the healthy was compared to those of the diseased cattle using 2- $\Delta \Delta \mathrm{Ct}$ calculation. qRT-PCR showed the CATHL4 transcript was expressed in both lymph node tissue and lung tissue in healthy and diseased cattle. In the infected cattle, the average transcription level in lymph nodes and lung tissues were respectively 19.42 (Fig. 3A) and 3.58 (Fig. 3B) times higher compared to that of the healthy ones. Besides, the expression level of CATHL4 in lymph node is higher than in lung tissue of diseased cattle.

To understand the function of gene, the relative expression level of CATHL4 in the lymph nodes and in lung tissues was compared within the same diseased cattle (Fig. 4) or the same healthy cattle (Fig. 5). 


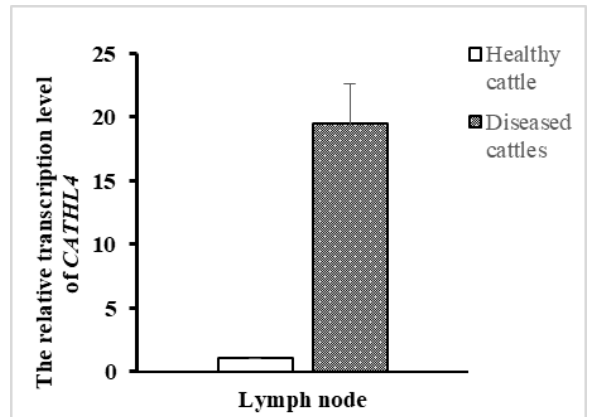

(A)

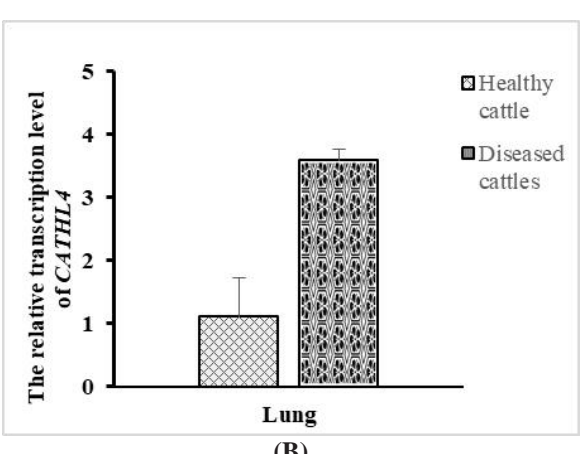

(B)

Figure 3: Relative transcription levels of CATHL4 lymph node (A) and lung tissue (B) were compared between the healthy and infectious cattle.

The bars indicate the standard error mean $( \pm$ SEM)

Comparison of CATHL4 gene expression in lung and lymph node tissue samples of diseased cattle

To compare the gene expression levels of CATHL4 gene in the diseased cattle and in different tissues with infectious status, data analysis of the relative transcription level of interested gene revealed the tissue specific expression using $2-\Delta \Delta \mathrm{Ct}$ method calculation. The CATHL4 transcription level in lymph node was higher than that in the lung tissue of the same cattle. CATHL4 transcriptions in lymph node tissues were different between two diseased cattle, being 11.42 and 35.33. However, the expression levels in lung tissues were almost the same in both diseased cattle, being 3.67 and 3.81 (Fig. 4).

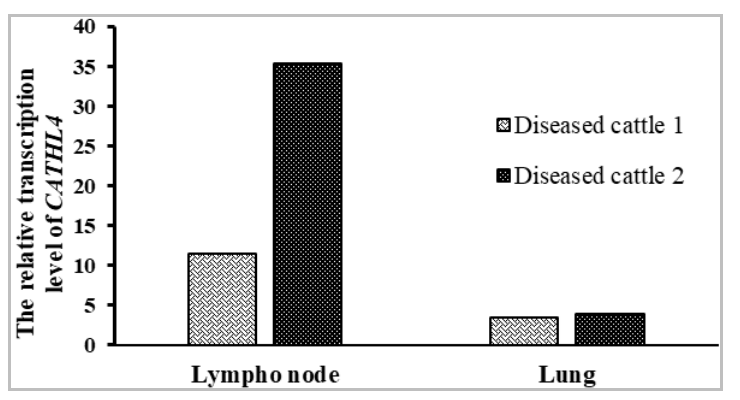

Figure 4. Comparison of transcription level of CATHL4 in lymph node and lung tissue samples in infected yellow cattle

The above results indicated that, in diseased cattle, CATHLA gene was expressed more abundantly in lymph node than in lung tissue and increased when induced by pathogen infection. However, in the healthy cattle, this gene transcription was not significantly increased in both lymph node and lung tissues. The CATHL4 gene's expression in these tissues clearly indicated that cathelicidin gene functioned in immune response and might play a role in immunity system of yellow cattle.

\section{Comparison of CATHL4 transcription level in lymph node and in lung tissues of the healthy samples}

As shown in Fig. 5, the expression CATHL4 gene in the same type of tissue was mostly similar among two healthy cattle, with higher level in lymph tissue than in lung tissue. On the other hand, the difference of expression between two healthy cattle is not significant for both types of tissue. This comparison was conducted using $\triangle \mathrm{Ct}$ method and $Y W H A Z$ as reference gene.

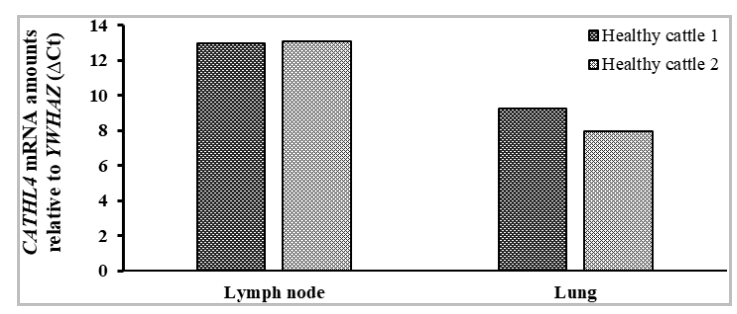

Figure 5. Relative transcription level of CATHL4 in lymph node and lung tissues of the healthy cattle compared to $Y W H A Z$ reference gene 
Lymph nodes are important for proper functioning of the immune system, acting as filters for foreign particles such as pathogens. Lymphocytes are primarily made up of B cells and $\mathrm{T}$ cells in lymph nodes. Expressed indolicidin transcript of CATHLA indicated that this antimicrobial peptide may play the role as defense host peptide. The abundant expression of the CATHL4 gene in diseased cattle indicated the participation of cathelicidins in immune activity that responds to pathogen infection and tissue specific expression.

\section{DISCUSSION}

Real-time PCR (qPCR) technique is considered as the most accurate and most reliable assessment of transcription expression. With its advantages such as sensitivity, real time detection of reaction progress, speed of analysis and precise measurement, this technique has been applied for research on gene function through transcription level. Determination of gene expression levels in specific tissues of the body or in individuals with different health states can help determine the potential role of genes in vivo.

Cathelicidins have been identified in several fish species and their mRNA expression was found to be increased after bacterial infection (Maier, 2008). Baumann et al. showed that the bovine cathelicidins were able to inhibit the growth of bacteria and enhance the sensing of nucleic acid by immune system of host. Certain bovine cathelicidins play a role in helping the innate immune system to sense nucleic acids and these peptides are relevant in development of future strategies to promote protection at mucosal surfaces against pathogen invasion (Baumann, 2017). In another research, analysis of expression of cathelicidin genes from the forest musk deer was revealed that the six functional genes were abundantly expressed in the spleen and lung. Moreover, the expression was different in response to abscesses. This result suggested that forest musk deer cathelicidins may play an important role in response to infections. (Zhang, 2019).

In this study, we used infectious and healthy samples to investigate whether the CATHL4 gene played a role in the immune response of the in indigenous Vietnamese cattle. The results indicated that, CATHL4 gene were abundantly expressed in tissues of the diseased cattle at a higher level compared to the healthy ones. In both infection and healthy states, the expression of CATHLA in lymph node was higher than in the lung. The results obtained from this study are consistent with many other studies evaluating the role of cathelicidin in the immune response. From this study, CATHL4 (indolicidin) can be considered to be participating in functions against infectious pathogens.

\section{CONCLUSION}

This result showed different transcription levels of CATHLA in lymph node and lung tissues, and increased transcripts in response to bacterial infection and suggested that indigenous bovine cathelicidin may be involved in immune system of Vietnamese indigenous cattle.

\section{ACKNOWLEDGMENT}

This study is financially supported by Vietnam National University, Hanoi and The Key Laboratory of Enzyme and Protein Technology, VNU University of Science (Grant number KLEPT18.02).

\section{REFERENCES}

Baumann A., Kiener M. S., Haigh B., Perreten V. Summerfield A., 2017. Differential ability of Bovine antimicrobial cathelicidins to Mediate nucleic acid sensing by epithelial cells. Front. Immunol. $8(59)$. https://doi.org/10.3389/fimmu.2017.00059

Brahma B., Patra M. C., Karri S., Chopra M., Mishra P., Chandra De B., Kumar S., Mahanty S., Thakur K., Poluri K. M., Datta T. K., De S., 2015. Diversity, Antimicrobial Action and Structure A ctivity Relationship of Buffalo 
Cathelicidins. Plos One. https://doi.org/ 10.1371/journal.pone.0144741

Broekman D. C., Frei D. M., Gylfason G. A., Steinarsson A., Jörnvall H., Agerberth B., Gudmundsson G. H., Maier V. H., 2011. Cod cathelicidin: Isolation of the mature peptide, cleavage site characterization and developmental expression. Developmental and Comparative Immunology, 35: 296-303.

Gillenwaters E. N., Seabury C. M., Elliott J. S., Womack J. E., 2009. Sequence analysis and polymorphism discovery in 4 members of the bovine cathelicidin gene family. $J$ Hered, https://doi.org/ 101093/jhered/esn112

Goossens K., Poucke M. V., Soom A. V., Vandesompele J., Zeveren A. V. and Peelman L. J, 2005. Selection of reference genes for quantitative real-time PCR in bovine preimplantation embryos. BMC developmental biology 5, 27, https://doi.org/10.1186/1471-213X-5-27

Livak K. J. 1997 (updated 2001). Relative quantification of gene expression: $\mathrm{ABI}$ Prism 7700 Sequence Detection System, Applied Biosystems User Bulletin \#2.

Livak K. J., Schmittgen T. D., 2001. Analysis of relative gene expression data using real-time quantitative PCR and the 2- $\Delta \Delta \mathrm{Ct}$ method. Methods, 25: 402-408.

Maier V.H., Dorn, K.V., Gudmundsdottir, B.K., Gudmundsson, G.H., 2008. Characterisation of cathelicidin gene family members in divergent fish species. Mol.Immunol. 45, 3723-3730
Shinnar A. E., Butler K. L., and Park H. J., 2003, Cathelicidin family of antimicrobial peptides: proteolytic processing and protease resistance. Bioorganic Chemistry 31, 425-436.

Zhang L., Jie H., Xiao Y., Zhou C., Lyu W., Bai W., 2019. Genomic Identification Expression Analysis of the and Cathelicidin Gene Family of the Forest Musk Deer. Animals, 9, 481; https://doi.org/10.3390/ani9080481

Mookherjee N., Brown K. L., Bowdish D. M., Doria S., Falsafi R., Hokamp K., Roche F. M., Mu R., Doho G. H., Pistolic J., Powers J. P., Bryan J., Brinkman F. S., Hancock R. E., 2006. Modulation of the TLR-mediated inflammatory response by the endogenous human host defense peptide LL-37. J Immunol, 176: 2455-2464.

Tomasinsig L., Zanetti M., 2005. The cathelicidins - structure function and evolution. Curr Protein Pept Sci.; 6: 2334. PMID: 15638766.

Whelehan C. J, Barry R. A., Meade K. G, Eckersall P. D., Chapwanya A., Narciandi F., Lloyd A. T. and O'Farrelly C., 2014. Characterisation and expression profile of the bovine cathelicidin gene repertoire in mammary tissue. BMC Genomics, 15: 128

Wuerth K., Hancock R. E., 2011. New insights into cathelicidin modulation of adaptive immunity. Eur J Immunol, 41: 2817-2819. 